\title{
Development of a self-care competence assessment form for the person with an intestinal stoma
}

Construção do formulário de avaliação da competência de autocuidado na pessoa com ostomia de eliminação intestinal

Construcción del formulario de evaluación de la competencia del autocuidado en la persona con ostomía de eliminación intestinal

Carla Regina Rodrigues da Silva*; Teresa Maria Silva Cardoso**; Ana Maria Rodrigues Gomes***; Célia Samarina Vilaça de Brito Santos****; Maria Alice Correia de Brito*****

\begin{abstract}
Background: An intestinal stoma implies multiple and significant changes that tend to be overcome through the development of ostomy self-care skills. The identification of the patient's specific needs during this adaptation process will help nurses' decisionmaking and contribute to a rigorous nursing diagnosis process, thus improving the quality and continuity of care delivery to this population group.

Objectives: To develop an instrument for assessing the self-care competence of the person with an intestinal stoma.

Methodology: Methodological study consisting of the development of a form. Content validity was ensured by expert review using a focus group. The form was applied to a convenience sample of 180 participants.

Results: A form was developed with 45 measurement indicators divided into 6 domains. It showed very good internal consistency (overall Cronbach's alpha $>.90$ ) and solid content validity.

Conclusion: The form proved to be a reliable and easy to use method to assess the development of self-care competence in people with an intestinal stoma.
\end{abstract}

Keywords: self-care; ostomy; colostomy; ileostomy; jejunostomy; nursing care

\section{Resumo}

Enquadramento: A criação de uma ostomia intestinal impõe à pessoa múltiplas e significativas mudanças que tendem a ser superadas através do desenvolvimento da competência de autocuidado ao estoma. Conhecer as necessidades específicas da pessoa a vivenciar este processo de adaptação auxiliará na tomada de decisão dos enfermeiros, imprimindo maior rigor ao processo de diagnóstico de enfermagem, com repercussões na melhoria e na continuidade da assistência a este grupo populacional. Objetivos: Construir um instrumento de avaliação da competência de autocuidado na pessoa com ostomia intestinal.

Metodologia: Estudo metodológico que consistiu na construção de um formulário. A validade de conteúdo foi garantida pela avaliação de peritos através de um focus group. O formulário foi aplicado a uma amostra de conveniência de 180 participantes.

Resultados: Formulário com 45 indicadores de medida, agrupados em 6 domínios, apresentando muito boa consistência interna (alfa de Cronbach global > 0,90) e reconhecida validade de conteúdo.

Conclusão: O formulário construído mostrou ser fidedigno e de fácil aplicação na avaliação do desenvolvimento da competência de autocuidado à pessoa com ostomia intestinal.

Palavras-chave: autocuidado; ostomia; colostomia; ileostomia; jejunostomia; cuidados de enfermagem

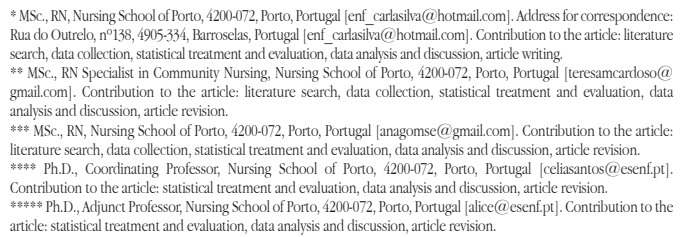
Rua do Outrelo, $\mathrm{n}^{\circ} 138,4905.334$, Barroselas, Portugal [enf carlasiviva $@$ hotmail.coml. Contribution to the article: literature search, data collection, statistical treatment and evaluation, data analysis and discussion, article writing. "'MSc, RN Specialist in Community Nursing, Nursing School of Porto, 4200-072, Porto, Portugal Iteresamcardoso@ analysis and discussion, article revision

"*** MSc, RN, Nursing School of Porto, 4200-072, Porto, Portugal lanagomse@gmail.com]. Contribution to the article

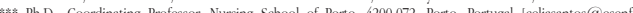
Contribution to the articles statistical treatment and evaluation, data analysis and discussion, article revision. article: statistical treatment and evaluation, data analysis and discussion, article revision.

\section{Resumen}

Marco contextual: La creación de una ostomía intestinal impone al paciente múltiples y significativos cambios, que tienden a superarse a través del desarrollo de la competencia del autocuidado del estoma. Conocer las necesidades específicas de la persona que vive este proceso de adaptación ayudará en la toma de decisiones de los enfermeros y exigirá un mayor rigor en el proceso del diagnóstico de enfermería, lo que repercutirá en la mejora y la continuidad de la asistencia a este tipo de pacientes.

Objetivos: Construir un instrumento de evaluación de la competencia del autocuidado en el paciente con ostomía intestinal

Metodología: Estudio metodológico que consistió en construir un formulario. La validez del contenido la garantizó un grupo de expertos a través de un focus group. El formulario se aplicó a una muestra de conveniencia de 180 participantes.

Resultados: Formulario con 45 indicadores de medida, agrupados en 6 dominios y que presentan muy buena consistencia interna (alpha global $>0,90$ ) y validez de contenido reconocida.

Conclusión: El formulario construido demostró que es fidedigno y de fácil aplicación en la evaluación del desarrollo de la competencia del autocuidado de la persona con ostomía intestinal.

Palabras clave: autocuidado; ostomía; colostomía; ileostomía; yeyunostomía; cuidado de enfermería

Received for publication: 28.04 .16

Accepted for publication: 07.11.16 


\section{Introduction}

The development of a temporary or permanent intestinal ostomy can triggera process of health/disease transition due to the patients' need to incorporate the changes inherent to this new life condition, forcing them to redefine themselves. This type of transition depends on the patient's self-care competence, with an impact not only on their motor function, but also on their cognitive and affective domains. An ostomy is not labeled as a chronic condition, but living with an ostomy requires patients to have the same selfmanagement skills and knowledge (Registered Nurses' Association of Ontario, 2009).

The development of the necessary ostomy selfcare skills is a health need that requires a strong involvement of nursing care. Through the assessment of ostomy self-care skills, it is possible to identify the patients' needs and, therefore, adapt nursing interventions. Despite the relevance of this topic and the documented scientific evidence which suggests that patients should develop ostomy self-care skills, there is no instrument allowing nurses to assess the development of these skills from the preoperative phase to community settings. The existing instruments address the process of developing ostomy selfcare skills in a rigid manner, to the extent that they define the needs of the person with an intestinal stoma and the phases or even the days when these manifest beforehand. The lack of such instrument is an obstacle to the assessment of the evolution of selfcare skills of the person with an intestinal stoma, to a complete and systematic data collection and, as a result, to the continuity of nursing care delivery.

This nursing research study was developed with the purpose of developing an instrument for assessing the development of self-care skills of the person with an intestinal stoma. This instrument, which is designed to be applied by nurses during the patients' process of adaptation to this condition, is a tool capable of systematizing data collection and assisting in the process of planning nursing care.

\section{Background}

The Portuguese terms estoma, estomia, ostoma or ostomia (in English, stoma, ostomy) are used interchangeably to refer to the exteriorization of any hollow viscera through the body; these terms are identified with a unique prefix depending on the body segment where they are located. Thus, intestinal stomas include the colostomy, the ileostomy, and the jejunostomy (Santos, 2005).

It is undeniable that ostomy patients need time to accept the stoma and the associated devices, as well as to develop specific self-care skills. In this context, competency should be understood as the acquisition of knowledge, skill, and attitude (Bloom as cited in Metcalf, 1999). Far from being limited to the demonstration of cognitive, psychomotor or affective skills, competency is the simultaneous application of these skills in given a situation, thus being understood as knowledge-in-action. Patients living with an ostomy have self-care skills when they can mobilize, integrate and transfer knowledge, resources and skills to stoma care. In turn, the concept of self-care, when applied to the person with an ostomy, can be defined as the patient's competence to apply management skills to stoma care (O'Connor, 2005).

The current concerns around the topic (magnitude of the problem), the state-of-the-art (level of knowledge), and the need to periodically assess the level of competency of people with chronic conditions (severity of the problem) are reasons enough for the existing scientific studies to encourage the development of instruments that use everyday language. This type of tool is essential for the systematization of the data collection process on the assessment of self-care skills, thus contributing to professional nursing practices. On the contrary, most of the existing instruments targeting the person with an ostomy include fields related to ostomy self-care skills in different phases of the perioperative period or divide them into a daily schedule, analyzing the adaptation process in a rigid and standardized way. Other instruments are very specific because they are limited to a single area of competency or one phase of the perioperative period (usually the postoperative phase), and often focusing on the complications associated with the ostomy and the peristomal skin. Examples of these instruments include the Ostomy Care and Management Clinical Best Practice Guidelines (Registered Nurses' Association of Ontario, 2009), the Toronto Informational Needs Questionnaire (O'Connor, Coates \& O'Neill, 2010), the Algorithm for Ostomy Care (Beitz et al., 2010), and the Ostomy Skin Tool (Martins et al., 2010). 
The key to the rehabilitation process of the person living with an ostomy is the assessment of their actual and/or potential needs; health professionals who devote themselves to analyzing these needs will be able to provide a better response (O'Connor, Coates, \& O'Neill, 2010). Due to their importance in care planning, the data collected on the acquisition of skills by the person living with an ostomy should be accurately recorded (Law, Akroyd \& Burke, 2010) so that they can reflect the evolution of the learning process.

\section{Research question}

This study was developed based on the following research question: How should self-care skills of the person with temporary or permanent intestinal stoma be assessed?

\section{Methodology}

A methodological study was developed taking into account the study objective and the nature of the topic under analysis. To assess the self-care skills of the person with an intestinal ostomy, we developed a measurement instrument capable of assessing this competency. This instrument was developed based on the guidelines of Freixo (2011), and the steps defined by Hulley, Cummings, Browner, and Grady (2015).

The instrument was developed as a form, which Marconi and Lakatos (2010) define as a roadmap with questions. This form should be completed by the researcher or other person duly informed, and based on the in-person observation and questioning of the respondent. Although this data collection technique does not ensure anonymity and allows less freedom in the answers, it seemed to be the best strategy for achieving the objective of this study to the extent that this allows for the application of the instrument to illiterate people and the assessment of self-care skills through the nurse's clinical judgment, by comparing the patient's performance with predefined outcome indicators of ostomy self-care skills.

The form was developed in different stages:

$1^{\text {st }}$ stage - The form development began with the definition of the key concepts of the study (Hulley et al., 2015). According to Freixo (2011), this is the first phase of development of a measurement instrument, since the research questions are based on the concepts. So, the concepts of competency, self-care and intestinal ostomy were defined.

$2^{\text {nd }}$ stage - The second phase of form development consisted of a review of the evidence on self-care skills of the person with an intestinal stoma, particularly published measurement instruments that addressed similar or related topics and included the main variables of this study, according to the guidelines of Freixo (2011) and Hulley et al. (2015). The authors explain that this review is essential to understand other researchers' experiences and be aware of certain formulations.

$3^{\text {rd }}$ stage - In parallel with the $2^{\text {nd }}$ stage, we identified the indicators related to each concept, since, as Freixo (2011) advocates, after the definition of the concepts, these must be decomposed by selecting the indicators that will determine the questions to be asked.

We selected the indicators based on the guidelines of the Nursing Outcomes Classification (Moorhead, Johnson, Maas, \& Swanson, 2010) related to the areas knowledge: ostomy care and ostomy self-care. In addition, the indicators derived from this analysis were compared with those that emerged from the literature review and the researchers' clinical experience.

$4^{\text {th }}$ stage - After the definition of the indicators, we organized them and assigned meanings based on the clinical concept under analysis. Therefore, we decided to follow the recommendations by Schumacher, Stewart, Archbold, Dodd, and Dibble (2000) related to listing the properties, dimensions and indicators of change in the family caregiver's role. In both situations (the transition to the role of family caregiver and the transition to the person living with an ostomy), the transition is determined by the need to acquire new knowledge, skills and attitudes. We considered that, although Schumacher et al. (2000) focus their study on a different type of transition and care receiver, the general principles underlying the acquisition of skills were similar in both situations. These authors found a solid base of knowledge, capable of sustaining the development of instruments for assessing the family caregiver's competence to provide care. They identified nine dimensions in the role of family caregiver, and assigned measurement indicators to each dimension. These indicators consisted of observable characteristics of the care 
provided, reflecting the level of competency in care delivery.

Based on these authors' work and given the multidimensional nature of the self-care competence of the person with an intestinal stoma, we identified the following domains: knowledge, self-monitoring, interpretation, decision-making, execution, and negotiation and use of health resources. The previously identified indicators correspond to each of these domains.

$5^{\text {th }}$ stage - The indicators of the above-mentioned domains were measured using a single ordinal score on a 3-point Likert scale, which would show the different levels of self-care competence. The score ranged between 1 and 3, and the higher the score, the higher the competence demonstrated: 1 Demonstrates fully, 2 - Demonstrates partially, and 3 - Does not demonstrate.

Despite the argument that all form questions should be applicable to all respondents (Iarossi, 2011), the form included indicators that did not apply to all people, depending on the moment in time and the respondent. Taking into account that a person's ostomy self-care competence before the surgery is different a few months after the surgery, it is easy to understand that a form capable of assessing the development of this competence must include a broad set of indicators. These indicators should take into account the patient's individuality and the process as a whole, ensuring the correct assessment of the learning process of patients who, for example, in the same post-operative moment demonstrate different ostomy self-care skills. Therefore, nurses are responsible for assessing the extent to which the form can be applied in so far as "the reaction of each respondent should dictate the interviewer's choices regarding statements and subsequent strategies" (Iarossi, 2011, p. 245). As a result of the above-mentioned reasons and as a way to safeguard situations such as those described above, we choose to use the following grading scale for the categories: 1 - Demonstrates fully, 2 -Demonstrates partly, 3 - Does not demonstrate, and 4 - Not applicable.

$6^{\text {th }}$ stage - We added a first section for participant characterization through attribute variables (e.g. age, marital status, education, occupation, and professional status), clinical variables (e.g. clinical diagnosis, type of surgery, stoma type and duration), treatment variables (e.g. preoperative nursing consultation of stomal therapy, preoperative contact with stoma patients), and other variables such as the existence of a family caregiver. These are variables of interest since they allow extracting some hypotheses for future research, when considering the clinical context and treatment as facilitators or inhibitors of the process of development of self-care competence of patients with an intestinal stoma.

$7^{\text {th }}$ stage - In addition to the form, we also elaborated a guide for its completion, in order to define and explain the criteria and clarify any doubts for nurses other than the researchers, as well as to standardize its completion. Thus, this guide was elaborated with the purpose of contributing to interrater reliability, since well-informed and trained nurses are expected to come to the same conclusions when observing, for example, the same level of ostomy self-care abilities. Bowling (2014) explains that the results obtained by two or more raters must be consistent when there is an equal or similar population; in other words, the results must be determined by the characteristics of the object of the observation and not by the characteristics of the observers. Based on the premise that the form is completed by different nurses, the score assigned to each indicator should vary according to the level of ostomy self-care competence demonstrated by the patient, and not according to how each nurse applies the form.

$8^{\text {th }}$ stage - After the elaboration of a draft instrument, it was reviewed by a group of experts in the field of knowledge of the topic under study in order to assess its content validity. As recommended by Jayasekara (2012), the panel of experts was composed of five renowned experts in the areas of self-care and stomal therapy, since the analysis of complex issues requires the contribution from experts in the study field, preferably working in small focus groups. We selected two nurses specialized in stomal therapy working in the stomal therapy consultation of two hospitals in Porto, a Professor with a Ph.D. in Psychology with research conducted in oncology and stomal therapy, a nurse with a Master of Science in Nursing (MSN) degree working in a specialized unit for cancer patients with intestinal stomas and with research conducted in oncology and stomal therapy, and a nurse with a MSN degree with research conducted in self-care, who is also faculty member in a nursing school in Porto. This group of experts was able to analyze and reflect on both the form and the guide, which were previously 
sent by email. After their independent analysis, the five experts met in a focus group to analyze the form as a whole and its individual items, and to reach group consensus. We obtained total interrater agreement in the completion of an indicator related to the execution domain. The indicator recorta a placa de acordo com o tamanho da ostomia (Cuts the pad to fit the stoma size) was changed to recorta a placal penso de acordo com o tamanho da ostomia (Cuts the pad/dressing to fit the stoma size). No changes were made to the remaining form since the panel of experts reached total agreement.

The change suggested by the panel of experts was incorporated into the form, which was again sent by email for new analysis.

$9^{\text {th }}$ stage - After the experts reached an agreement concerning its structure and content, the form was also sent to a Portuguese language teacher for analysis, since, according to Iarossi (2011), the art of formulating effective questions/statements requires, among other aspects, language skills. After the process of content validity assessment of the form, we obtained pilot versions of the form and guide, which were submitted to pre-test.

At the end of the process of form development, we pre-tested the form in a group of 15 people: five people in the preoperative phase (namely, the day before surgery with potential intestinal stoma), and 10 people with an intestinal stoma in the postoperative phase (five people at hospital discharge, and five people in community settings). This would allow the form to be used by nurses at any moment of the patients' process of adaptation to the new condition, i.e. from the preoperative phase to community settings. During the pre-test, we discussed the form with the respondents, in order to identify any question that could be less clear or that could be seen as too intrusive. The form was applied by the researchers or the nurse practitioners, after being duly informed and their doubts were clarified.

The final version of the form Competência do Autocuidado à Ostomia de Eliminação Intestinal: Escola Superior de Enfermagem do Porto (CAOEI:ESEP), Self-Care Competence of the Person with an Intestinal Stoma: Nursing School of Porto) was applied to a sample of the target population (180 participants), with the purpose of conducting a preliminary study to understand the form applicability, rather than to assess its psychometric properties. The form was applied to 50 patients in the day before colorectal surgery with probable intestinal stoma, 50 patients after colorectal surgery with an intestinal stoma at hospital discharge, and 80 people with an intestinal stoma in community settings.

This sample was collected using the convenience sampling technique. The sample participants who met the following inclusion criteria were included in the study: individuals with a temporary or permanent intestinal stoma or who were referred for elective colorectal surgery with probable temporary or permanent intestinal stoma; having signed the informed consent form; being aged 18 years or over; and having agreed to participate in the study in a voluntary and informed way. We defined the following exclusion criteria: individuals who were totally dependent on stoma care and/or unable to develop the ostomy self-care competence due to cognitive impairment, which was assessed using a version of the Mini Mental State Examination (MMSE) validated and adapted to the Portuguese population (Guerreiro et al., 1994).

This study complied with the ethical principles for health research involving human beings. Data collection was authorized by the Health Ethics Committee of each institution involved in the study. All participants were asked to sign an informed consent form for participation in the study. Data confidentiality was ensured.

\section{Results}

The content validity of instruments used to measure the subjects' skills and knowledge should be assessed. The experts in the focus group agreed on the indicators and corresponding domains on the intestinal ostomy self-care competence included in the form, which were considered relevant and appropriate to measure the construct under analysis. In addition, the Portuguese teacher made no changes to the syntax or to the statements, which were considered to be correct and clear.

The intestinal ostomy self-care competence was accepted as a multidimensional concept consisting of six domains (knowledge, self-monitoring, interpretation, decision-making, execution, and negotiation and use of health resources), which correspond to the total of 45 outcome indicators. 
Similarly, no changes were made to the form as a result of the pre-test since there were no confusing or difficult to interpret statements. The domains and corresponding indicators were listed in a logical sequence that facilitated the application and completion of the form which, in some situations, particularly in the preoperative phase, was not applied beyond the knowledge domain.

The single ordinal score used to assess the intestinal ostomy self-care competence on a 3-point Likert scale proved to be useful in clinical practice because it allows identifying each participant's level of skill for each indicator.

Taking into account the construct under analysis and the fact that the instrument was developed to assess the performance of the person with intestinal stoma using a Likert-type scale, we decided to assess the instrument's reliability based on its internal consistency, by means of calculating Cronbach's alpha coefficient. The statistical analysis of the results obtained from the pilot study showed that the form had an overall Cronbach's alpha of .93 when applied at hospital discharge and a Cronbach's alpha of .91 when applied in community settings, which indicates a very good internal consistency (Ribeiro, 2010). It should be noted that the Cronbach's alpha coefficient obtained in the preoperative phase (.77) refers only to the knowledge domain, since none of the other domains were applied to the study participants. The Cronbach's alpha coefficient for the remaining domains of ostomy self-care competence was calculated when the form was applied at hospital discharge and in primary health care settings. Reliability scores in all domains were all above acceptable levels. Table 1 shows the Cronbach's alpha coefficients.

\section{Table 1}

Coefficient of internal consistency of the form and its domains on the day before surgery, at hospital discharge, and in community settings $(N=180)$

\begin{tabular}{lcc}
\hline Day before colorectal surgery with potential intestinal stoma $(n=50)$ & \\
\hline Form domain & Number of items & Cronbach's Alpha \\
Knowledge & 9 & .77 \\
\hline At hospital discharge $(n=50)$ & Number of items & Cronbach's Alpha \\
\hline Form domain & 9 & .74 \\
Knowledge & 7 & .84 \\
Self-monitoring & 4 & .77 \\
Interpretation & 4 & .74 \\
Decision-making & 17 & .63 \\
Execution & 4 & .90 \\
Negotiation & 45 & .93 \\
Overall form & & \\
\hline In community settings $(n=80)$ & Number of items & .82 \\
\hline Form domain & 9 & .76 \\
Knowledge & 7 & .79 \\
Self-monitoring & 4 & .74 \\
Interpretation & 4 & .74 \\
Decision-making & 17 & .71 \\
Execution & 4 & .91 \\
Negotiation & 45 & \\
Overall form & & .79 \\
\hline
\end{tabular}

\section{Discussion}

The lack of robustness of the research on the assessment of the specific self-care needs of people with intestinal stoma encouraged the development of this instrument, which is capable of assessing these needs with a view to enhancing the nursing diagnosis process and, consequently, the quality of the care provided to this growing population group. 
Therefore, it is essential to understand the challenges faced by the person with intestinal ostomy; however, accurate data must be systematically collected in order to identify the difficulties experienced by a person with an intestinal stoma. In the same way, the characteristics of the people living with an intestinal stoma should also be identified and analyzed since some of them are associated with the development of stoma complications.

The developed form (CAO-EL: ESEP) meets the requirements outlined above by allowing to assess the sociodemographic, clinical and treatment characteristics of people with intestinal stoma, as well as to assess their self-care competence and, therefore, their needs in this area. This assessment enables nurses to identify actual and potential difficulties in the process of acquiring new knowledge, skills and attitudes towards this new condition. In this sense, the form is a significant tool for nurses, by assisting them in the nursing process and helping them to identify what patients know about their clinical situation, how they interpret events, and how they transfer the information and self-care competence to their day-to-day.

Although the form has not been submitted to a validation process, it proved to be reliable due to its very good internal consistency (Ribeiro, 2010). The assessment of the Cronbach's alpha according to the areas of ostomy self-care competence always resulted in reliability values above .60 , which are considered acceptable values in scales with few items (Ribeiro, 2010).

With regard to reliability, stability could not be tested by means of a test-retest. Bowling (2014) describes the test-retest method, giving the example of the reproducibility of the responses to the scale over a period of time. In this study, the ostomy self-care competence is not expected to remain unchanged over time because we believe that the construct under analysis is not constant in time, i.e. the person with a stoma acquires knowledge, skills and attitudes that determine their level of ostomy self-care competence at different moments.

With regard to the validity of the instrument, namely its content validity, the form seems to include statements capable of representing the topic under study, and contributing to assess the observed behaviors, either based on the source from which the indicators were extracted (Classification of Nursing Outcomes) or on the consensus reached by the expert group.
Without disregarding the meaning, relevance and applicability of the instrument in nursing clinical practice, the form revealed some limitations related to the ordinal scoring of its Likert-type scale, its poor discriminatory power, and its reverse reasoning in the assessment. These weaknesses were only discovered during data processing, when small differences were obtained between the overall means of demonstration of ostomy self-care competence among the domains. The assessment of each domain per indicator, at the time of data collection, revealed no constraints concerning the accomplishment of the instrument's purpose. However, the calculation of the score assigned to each indicator, and subsequent overall mean of demonstration of the self-care competence for that domain, identified gaps that were imperceptible during the development and application of the form. This difficulty is mostly evident when the form is applied to research processes.

On the other hand, the reverse reasoning in the assessment scale $(1=$ demonstrates fully, $2=$ demonstrates partially, and $3=$ does not demonstrate) added some degree of difficulty to the result analysis, forcing a reverse interpretation, in which the lower the mean in the level of self-care competence, the higher the level of demonstration of that self-care competence, and vice-versa.

Based on the limitations discussed in the previous paragraphs, further studies should focus on the operationalization of the Likert-type scale adopted in this instrument, transforming it into a scale more sensitive to changes in the level of demonstration of the ostomy self-care competence. This scale should also be encoded according to the reasoning in which the higher the mean, the higher the level of demonstration of the self-care competence, and vice-versa.

Although the instrument has also been applied by nurses other than the researchers, the interrater agreement was not assessed. Therefore, further studies should explore this aspect, given its importance for measuring the external error resulting from the application of the form by different nurses.

These limitations were considered in the study conducted by Pinto, Santos, Brito, and Queirós (2016), who assessed the psychometric properties of the CAO-EI: ESEP form, whose process of development is addressed in this article. The authors concluded that this form has good psychometric indicators, 
suggesting that it can be used by nurses, and that it is a useful tool for the nursing diagnosis process.

Moreover, the form should also be applied to other samples, which should be random and have heterogeneous characteristics, and its psychometric properties should be analyzed, with a view to increasing the reliability and validity of the results obtained with its application.

Finally, it should be mentioned that this form is the first instrument for supporting nurses in their decisions concerning care delivery to patients with intestinal stoma. Since it can be applied at any time during the intestinal stoma patient's process of developing the self-care competence, this form provides a simple and efficient assessment scheme, making it more consistent. Therefore, it is a useful tool by allowing an increasingly specific assessment, evolving from the domains of the intestinal ostomy self-care competence to the indicators representing each domain. The form will, in turn, facilitate the communication between the several health care professionals involved in the provision of care to the patient with an intestinal stoma, namely nurses, thus contributing to strengthen the continuity of care.

\section{Conclusion}

Nursing, as a science with its own disciplinary knowledge, should use the knowledge resulting from nursing research and apply it in clinical practice. This requires not only research but also a conceptual framework that guides the research and represents the results obtained through nursing theory.

Ostomy patients experience a health/disease transition to the extent that they need to incorporate the demands and changes imposed by the new condition into their life. These changes are not only physical, but also psychological, social and cultural, demanding a comprehensive and integrated approach to patients with a stoma, without neglecting their needs. The literature reports that the development of ostomy self-care competence is a predictor of adaptation, and the nurse's intervention can make a difference in this process.

This form (CAO-EI: ESEP) can be applied from the preoperative phase to community settings, and it is sensitive to the level of ostomy self-care competence demonstrated by patients throughout their adaptation process. Its use allows systematizing the collection of data on the patient with an intestinal stoma, and the data collected through its application allow for a more accurate nursing diagnosis process. This means that instruments such as this form are essential to improve the standardization of diagnostic and assessment criteria that can support nurses' decision-making process and nursing care continuity.

The use of this form (CAO-EI: ESEP) can contribute to the systematic and regular production of indicators capable of measuring health outcomes resulting from the contribution of the nursing care provided to patients with an intestinal stoma. In addition, it allows identifying the more vulnerable ostomy patients, who are at risk of developing an inadequate process of adaptation to the stoma. This knowledge is essential for the mobilization and coordination of resources with the purpose of meeting the needs of the person with an intestinal stoma.

\section{References}

Beitz, J., Gerlach, M., Ginsburg, P., Ho, M., McCann, E., Schafer, V., ... Turnbull, G. (2010). Content validation of a standardized algorithm for ostomy care. Ostomy Wound Management, 56(10), 22-38. Retrieved from http://www.o-wm.com/ content/content-validation-standardized-algorithm-ostomycare

Bowling, A. (2014). Research methods in health: Investigating bealth and health services ( $4^{\text {th }}$ ed.). New York, USA: McGrawHill Education.

Freixo, M. (2011). Metodologia científica, fundamentos, métodos e técnicas ( $3^{\text {a }}$ ed.). Lisboa, Portugal: Instituto Piaget.

Guerreiro, M., Silva, A., Botelho, M., Leitão, O., Castro-Caldas, A., \& Garcia, C. (1994). Adaptação à população portuguesa da tradução do Mini Mental State Examination. Revista Portuguesa de Neurologia, 1(9), 9-10.

Hulley, S., Cummings, S., Browner, W., \& Grady, D. (2015). Delineando a pesquisa clínica ( $4^{\mathrm{a}} \mathrm{ed}$.). Porto Alegre, Brasil: Armed.

Iarossi, G. (2011). O poder da concepção em inquéritos por questionário. Lisboa, Portugal: Fundação Calouste Gulbenkian.

Jayasekara, R. (2012). Focus groups in nursing research: Methodological perspectives. Nursing Outlook, 60(6), 411416. doi:10.1016/j.outlook.2012.02.001 
Law, L., Akroyd, K., \& Burke, L. (2010). Improving nurse documentation and record keeping in stoma care. British Journal of Nursing, 19(21), 1328-1332. doi:10.12968/ bjon.2010.19.21.80002

Marconi, M., \& Lakatos, E. (2010). Fundamentos de metodologia científica ( $7^{\mathrm{a}}$ ed.). São Paulo, Brasil: Editora Atlas.

Martins, L., Ayello, E., Claessens, I., Steen Hansen, A., Hentze Poulsen, L., Sibbald, R., \& Jemec, G. (2010). The ostomy skin tool: Tracking peristomal skin changes. British Journal of Nursing, 19(15), 961-964. doi:10.12968/ bjon.2010.19.15.77691

Metcalf, C. (1999). Stoma care: Empowering patients through teaching practical skills. British Journal of Nursing, 8(9), 593-600. doi:10.12968/bjon.1999.8.9.6621

Moorhead, S., Johnson, M., Maas, M., \& Swanson, E. (2010). NOC: Classificação dos resultados de enfermagem ( $4^{\text {th }}$ ed.). Rio de Janeiro, Brasil: Mosby Elsevier.

O'Connor, G. (2005). Teaching stoma-management skills: The importance of self-care. British Journal of Nursing, 14(6), 320-324. doi:10.12968/bjon.2005.14.6.17800.

O'Connor, G., Coates, V., \& O'Neill, S. (2010). Exploring the information needs of patients with cancer of the rectum.
European Journal of Oncology Nursing, 14(4), 271-277. doi:10.1016/j.ejon.2010.01.024

Pinto, I., Santos, C., Brito, M., \& Queirós, S. (2016). Propriedades psicométricas do formulário Desenvolvimento da competência de autocuidado da pessoa com ostomia de eliminação intestinal. Revista de Enfermagem Referência, 4(8), 75-84. doi:10.12707/RIV15044

Ribeiro, J. (2010). Metodologia de investigação em psicologia e saúde ( $3^{\mathrm{a}}$ ed.). Porto, Portugal: Legis Editora/Livpsic.

Registered Nurses' Association of Ontario. (2009). Ostomy care and management: Clincal best practice guidelines. Toronto, Canada: Author.

Santos, V. (2005). A estomaterapia através dos tempos. In V. Santos \& I. Cesaretti (Eds.), Assistência em estomaterapia, cuidando do ostomizado (pp.1-17). São Paulo, Brasil: Atheneu.

Schumacher, K., Stewart, B., Archbold, P., Dodd, M., \& Dibble, S. (2000). Family caregiving skill: Development of the concept. Research in Nursing \& Health, 23(3),191-203. doi:10.1002/1098-240X(200006)23:3<191::AID-NUR3> 3.0.CO;2-B 
